\section{Cartographical Needs of the Airman}

THE activities of the Institute of Navigation include the investigation of various problems by working-parties under the general guidance of the technical committee, and several of these were referred to by Rear-Admiral A. Day, Hydrographer of the Navy, in his presidential address to the Institute. One working-party has undertaken to inquire into the precise requirements the airman needs of his maps and charts. The nautical chart has been built up to its present shape by many centuries of knowledge and experience of what the seaman wants. The air chart, like aviation itself, has grown up quickly, so that just what it should be like and exactly what is wanted of it has not been so easy to establish without question. The basis from which the Institute's working-party proposes to begin its investigations is one that accepts air navigation as it is to-day, but does not necessarily relate it to a system which uses charts in their present form. This means that their examinations will go much deeper than merely questioning whether, say, a map used for aircraft operating at a height of some $40,000 \mathrm{ft}$. should give the characteristics of lighthouses, or should show the 100-fathom line. Another problem is how to determine the quickest flight-path from one place to another, a problem which bears directly on the economy and efficiency of navigation in long-distance flights. A workable method of being able to determine, for any given set of meteorological conditions, the route of least time would be of considerable assistance to air operators. For some time now the Institute has had a working-party investigating the whole problem of determining the optimum flight-path; the task is a long one, partly because the aim is to produce a practical method which will offer clear advantages over those used in flight-planning to-day.

\section{Oil in Pakistan}

A SPEECH on the development of the oil industry in Pakistan was recently given in Karachi by M. J. Condon, chairman of the board of directors of Pakistan Petroleum, Ltd.' The sole producing region is the Potwar Basin, south-west of Rawalpindi, where four fields are established-Khaur, Dhulian, Balkassar and Joya Mair - but production is relatively small. Exploration is, however, active, six major tests being in operation at Bains and Chak Naraung in Punjab, at Sui in Baluchistan, at Patharia and Sylhet in East Bengal, and at Patiya near Chittagong. Mr. Condon's forecast on these prospects does not, however, appear particularly optimistic. As he rightly points out, prospecting costs in Pakistan are fifteen times what they are in the United States, primarily because all plant and equipment has to be shipped to the former country from overseas whereas "in America these things are available to the end of a telephone line", a pertinent comment on petroleum economics in other countries besides Pakistan. There is the prospect of a refinery being erected in Karachi, and a technical commission is being set up to review the whole situation. It is clear that the Pakistan Covernment and the industrial enterprises concerned are doing everything possible to develop petroleum resources in this geologically difficult territory.

\section{An Atlas of the Asclepiadaceæ}

UNDER this title, and with the help of some seventeen maps, Prof. R. Good (New Phytologist, 51,
198 ; 1952) has illustrated the distribution of the family, sub-families, tribes and selected genera of this highly distinctive group of tropical plants. The Asclepiadaceæ, by some taxonomists included in the order Apocynales, include perennial herbs, undershrubs, shrubs and climbers, all having a specialized pollen-transfer mechanism. Because of their particular and highly unusual features, the two constituent sub-families thus afford very useful materials for geographical study. The maps represent a summation of all available information regarding the distribution of the family. The family has a general distribution both in the Old and New World tropics, and of its two sub-families the smaller is confined to the old World, while the larger is present in both hemispheres. The family, however, is poorly represented in isolated islands. The proportion of narrowly distributed or endemic genera is very high, some being very local; that of endemic species is even higher, no such species being common to both worlds.

\section{A New Circumpolar Plant Species in Scotland}

WITH the discovery in 1951 of Diapensia lapponica L. (Ericales) at 2,500 ft. in the Arisaig district of Inverness-shire, Scotland, a new species, genus and family have been added to the British flora. Several hundred specimens have now been observed in this locality, the habitat being completely exposed, on stony and gravelly schists, and with a rainfall of 120 inches. D. lapponica is one of the small group of circumpolar, aretic-montane species - a group not represented in the mountains of Central Europewith a wide distribution in the several continental and insular areas in the Arctic region (see J. Grant Roger, "Diapense lapponica in Scotland", Trans. Bot. Soc., Edin., 36, Pt. 1, 34; 1952).

\section{N.P.L. Colour Temperature Scale}

IN July of this year the Director of the National Physical Laboratory announced that in future the 1948 International Temperature Scale would be used in assigning colour temperatures to light sources calibrated at the Laboratory. Previously, the 1927 International Temperature Scale had been used. The Laboratory has now issued the following comparisons and conversion factors. Corresponding values of temperatures on the two scales, in the range of importance in the calibration of tungsten filament lamps, are as follows:

$\begin{array}{ll}1927 \text { Scale } & 1948 \text { Scale } \\ 1500 \cdot 6^{\circ} \mathrm{K} . & 1500^{\circ} \mathrm{K} . \\ 2003 \cdot 8 & 2000 \\ 2508 \cdot 6 & 2500 \\ 3015 \cdot 1 & 3000 \\ 3523 \cdot 7 & 3500\end{array}$

If a lamp has been found by calibration to give a particular value of colour temperature on the 1927 Scale when it is run at a certain voltage $V$, the voltage to give the same numerical value of colour temperature on the 1948 Scale is obtained by multiplying $V$ by the factor shown in the following table:

$\begin{array}{cc}\begin{array}{c}\text { Colour } \\ \text { temperature } \\ \left({ }^{\circ} \mathbf{K} .\right)\end{array} & \begin{array}{c}\text { Multiplication } \\ \text { factor for voltage }\end{array} \\ 1500 & 1 \cdot 001 \\ 2000 & 1 \cdot 005 \\ 2500 & 1.009 \\ 3000 & 1.014 \\ 3500 & 1.019\end{array}$

These factors may be taken as correct to about onetenth of one per cent.

Illuminant $A$. The factor by which the voltage of a lamp calibrated at $2848^{\circ} \mathrm{K}$. on the 1927 Scale must. 